\title{
$\triangle$ Np63a down-regulates c-Myc modulator MM1 via E3 ligase HERC3 in the regulation of cell senescence
}

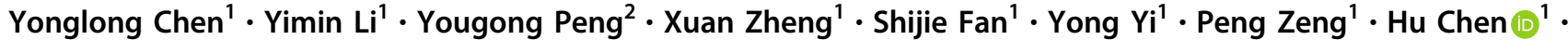 \\ Han Kang ${ }^{1} \cdot$ Yujun Zhang ${ }^{1} \cdot$ Zhi-Xiong Xiao $^{1} \cdot$ Chenghua Li $^{1}$
}

Received: 23 October 2017 / Revised: 20 April 2018 / Accepted: 8 May 2018 / Published online: 7 June 2018

(c) ADMC Associazione Differenziamento e Morte Cellulare 2018

\begin{abstract}
p63 and c-Myc are key transcription factors controlling genes involved in the cell cycle and cellular senescence. We previously reported that $\mathrm{p} 63 \alpha$ can destabilize MM1 protein to derepress c-Myc, resulting in cell cycle progress and tumorigenesis. However, how the proteasomal degradation of MM1 is facilitated remains unclear. In the present study, we identified a novel E3 ligase, HERC3, which can mediate ubiquitination of MM1 and promote its proteasome-dependent degradation. We found that $\triangle \mathrm{Np} 63 \alpha$ transcriptionally up-regulates HERC3 and knockdown of HERC3 abrogates $\Delta$ Np63 $\alpha$ induced down-regulation of MM1. Either overexpression of MM1 or ablation of HERC3 induces cell senescence, while knockdown of MM1 rescues cell senescence induced by deficiency of either $\Delta \mathrm{Np} 63 \alpha$ or HERC 3 , implicating the involvement of the $\Delta \mathrm{Np} 63 \alpha / \mathrm{HERC} 3 / \mathrm{MM} 1 / \mathrm{c}-\mathrm{Myc}$ axis in the modulation of cell senescence. Additionally, our Oncomine analysis indicates activation of the $\Delta \mathrm{Np} 63 \alpha / \mathrm{HERC} 3 / \mathrm{MM} 1 / \mathrm{c}-\mathrm{Myc}$ axis in invasive breast carcinoma. Together, our data illuminate a novel axis regulating cell senescence: $\triangle \mathrm{Np} 63 \alpha$ stimulates transcription of E3 ligase HERC3, which mediates ubiquitination of c-Myc modulator MM1 and targets it to proteasomal degradation; subsequently, c-Myc is derepressed by $\Delta \mathrm{Np} 63 \alpha$, thereby cell senescence is modulated by this axis. Our work provides a new interpretation of crosstalk between p63 and c-Myc, and also sheds new light on $\Delta \mathrm{Np} 63 \alpha$-controlled cell senescence and tumorigenesis.
\end{abstract}

\section{Introduction}

The p63 gene, a member of the p53 family, encodes a variety of protein products, which are transcription factors playing key roles in cell proliferation, cell survival, and

These authors contributed equally: Yonglong Chen, Yimin Li, Yougong Peng.

Edited by P. Salomoni

Electronic supplementary material The online version of this article (https://doi.org/10.1038/s41418-018-0132-5) contains supplementary material, which is available to authorized users.

Chenghua Li

lichenghua@scu.edu.cn

1 Center of Growth, Metabolism and Aging, Key Laboratory of BioResource and Eco-Environment of Ministry of Education, College of Life Sciences, Sichuan University, Chengdu 610064 Sichuan, China

2 Department of General Surgery, The Second People's Hospital of Jingmen, Jingmen 448000 Hubei, China tumorigenesis. Among these isoforms, $\Delta \mathrm{Np} 63 \alpha$ is the predominant one expressed in somatic cells, especially in the epithelial basal layer in embryonic ectoderm and ectodermderived tissues or organs [1-7]. Owing to the lack of a full transactivation (TA) domain at their $\mathrm{N}$ termini, $\Delta \mathrm{N}$ isoforms of p63, including $\Delta N p 63 \alpha$, were previously assumed to be merely antagonists of p53 as well as TA isoforms of p63 and p73 [1, 8.]. However, mounting evidence demonstrates that $\Delta \mathrm{Np} 63 \mathrm{~s}$ can also stimulate a vast body of target genes involved in cell proliferation, survival, differentiation, and motility [9-12]. Like TAp63 $\alpha, \Delta \mathrm{Np} 63 \alpha$ contains a unique $\mathrm{C}$ terminus comprised of a sterile alpha motif and a transinhibitory domain, which mediates protein interaction and transactivity regulation, conferring $\mathrm{p} 63 \alpha$ some functions distinct from those of other isoforms $[1,7,13]$.

Another important transcription factor involved in the cell cycle and tumorigenesis is c-Myc, which controls transcription of a large number of genes in various animals [14-16]. In our previous study, we reported that p63 $\alpha$ can promote proteasome-dependent degradation of c-Myc modulator MM1, resulting in derepression of c-Myc and the cell cycle [17]. However, the underlying mechanism 
remains obscure. In the present study, we identified HERC3 (HECT and RLD containing E3 ubiquitin protein ligase 3) as a novel E3 ligase which mediates ubiquitination of MM1 and promotes its proteasomal degradation. Further investigation revealed that $\Delta \mathrm{Np} 63 \alpha$ transactivates HERC3, and knockdown of HERC 3 abrogates $\Delta \mathrm{Np} 63 \alpha$-induced downregulation of MM1 protein levels. We found that either overexpression of MM1 or knockdown of HERC3 induces cell senescence, which is an important process in preventing cancer development and promoting organismal aging. Intriguingly, knockdown of MM1 can significantly rescue cell senescence induced by ablation of either $\Delta \mathrm{Np} 63 \alpha$ or HERC3. Oncomine analysis demonstrates that the $\Delta \mathrm{Np} 63 \alpha /$ HERC3/MM1/c-Myc pathway is activated in invasive breast carcinoma. These data suggest a crucial role of the $\Delta \mathrm{Np} 63 \alpha / \mathrm{HERC} 3 / \mathrm{MM} 1 / \mathrm{c}-\mathrm{Myc}$ axis in the $\Delta \mathrm{Np} 63 \alpha-$ mediated modulation of cell senescence and tumorigenesis.

\section{Materials and methods}

\section{Cell culture, drug treatment, and MTS assay}

H1299, HEK293T, and FaDu cells were maintained in Dulbecco's modified Eagle's medium (DMEM, Hyclone) supplemented with $10 \%$ fetal bovine serum (Hyclone) and $1 \%$ penicillin/streptomycin (Hyclone). MCF-10A cells were maintained in DMEM/F12 (Hyclone), supplemented with $20 \mathrm{ng} / \mathrm{ml}$ epidermal growth factor (Invitrogen), $100 \mathrm{ng} / \mathrm{ml}$ cholera toxin (Sigma), $10 \mathrm{ng} / \mathrm{ml}$ insulin (Sigma), $500 \mathrm{ng} / \mathrm{ml}$ hydrocortisone (Sigma), 1\% penicillin/streptomycin (Hyclone), and 5\% horse serum (Hyclone). All cells were cultured at $37^{\circ} \mathrm{C}$ in a humidified $5 \% \quad \mathrm{CO}_{2}$ incubator. MG132 and cycloheximide (CHX) were purchased from Sigma. The MTS (3-(4,5-dimethylthiazol-2-yl)-2,5-diphenyltetrazolium bromide) assay was performed to measure cell growth and obtain a growth curve, as previously described [18].

\section{Cell transfections and immunoblot analysis (IB)}

Plasmids of pCMV-Flag-MM1, pLVX-MM1, pcDNA$\Delta \mathrm{Np} 63 \alpha$, and pcDNA- $\Delta$ Np63 $\alpha(\mathrm{C} 306 \mathrm{R})$ have been described previously [9, 17]. Myc-tagged HERC3 (Wt HERC3) and its C1018A mutant (Mut HERC3) in pCMV vectors were obtained from Dr. Hochrainer [19]. H1299 or HEK293T cells with 50\% confluency in 6-well plates were transfected with $1 \mu \mathrm{g}$ of indicated plasmids with $3 \mu \mathrm{L}$ LipoPlus (Beijing Sage Creation Science Co, LTD). Then, $24 \mathrm{~h}$ post transfection, cells were collected, washed with phosphate-buffered saline, and resuspended in EBC250 lysis buffer (50 mM Tris-HCl, pH 8.0, $250 \mathrm{mM} \mathrm{NaCl}, 0.5 \%$ Nonidet P-40, 0.2\% phenylmethylsulfonyl fluoride (PMSF),
$2 \mu \mathrm{g} / \mathrm{ml}$ leupeptin, $2 \mu \mathrm{g} / \mathrm{ml}$ aprotinin, $50 \mathrm{mM} \mathrm{NaF}$, and 0.5 $\mathrm{mM} \mathrm{Na} \mathrm{VO}_{4}$ ). Protein concentration was determined using the Bio-Rad protein assay reagent (Bio-Rad). An equal amount of protein (about $50 \mu \mathrm{g}$ total protein) was loaded into each lane, separated on a $10 \%$ sodium dodecyl sulfate-polyacrylamide gel electrophoresis (SDS-PAGE), transferred to polyvinylidene difluoride membrane (BioRad), and hybridized to an appropriate primary antibody and horseradish peroxidase-conjugated secondary antibody for subsequent detection with ECL (Millipore). Immunoblot analysis was performed with anti-MM1 (Abcam, ab129116), anti-HERC3 (Abcam, ab56440), anti-p63 (Cell Signaling Technology, cst-13109), anti-CDK4 (Santa Cruz Biotechnology, sc-260), anti-PAI-1 (Cell Signaling Technology, cst-11907), anti-c-Myc (Epitomotis, 1472-1), antiMyc-tag (Santa Cruz Biotechnology, sc-40), anti-Flag (Abcam, ab49763), anti-Ubiquitin (Cell Signaling Technology, cst-3936), anti-GAPDH (Hua-An Biotechnology, R1208-3), and anti-Actin (Cell Signaling Technology, cst1615).

\section{Immunoprecipitation (IP) and ubiquitination assays}

For the co-immunoprecipitation (Co-IP) experiment, H1299 cells were co-transfected to express Myc-tagged HERC3 or (and) Flag-tagged MM1. Cells were lysed in ice-cold lysis buffer $(20 \mathrm{mM}$ Tris- $\mathrm{HCl}, \mathrm{pH} 7.8,125 \mathrm{mM} \mathrm{NaCl}, 5 \mathrm{mM}$ $\mathrm{MgCl}_{2}, 0.25 \%$ Nonidet P-40, $1 \mathrm{mM}$ PMSF, $10 \mu \mathrm{g} / \mathrm{ml}$ leupeptin, $10 \mu \mathrm{g} / \mathrm{ml}$ aprotinin, and $1 \mathrm{mM}$ dithiothreitol) for 30 min on ice. Lysates were cleared by centrifugation at $13,000 \mathrm{rpm}$ for $20 \mathrm{~min}$. Protein concentration was determined using the Bradford protein assay reagent (Bio-Rad). Then, $2 \mathrm{mg}$ of total proteins from cell lysates were incubated with anti-Myc-tag or anti-Flag using normal mouse IgG as control at $4{ }^{\circ} \mathrm{C}$ for $8 \mathrm{~h}$, and the immune complexes were precipitated with protein G-agarose at $4{ }^{\circ} \mathrm{C}$ for $2 \mathrm{~h}$. The immunoprecipitates were washed with lysis buffer, separated by SDS-PAGE, and subjected to IB for p63 and MM1.

For ubiquitination analysis, H1299 cells were transfected with pCMV-Flag-MM1 and pcDNA3-ubiquitin, plus pCMV-Myc-HERC3, pLKO.1-shHERC3 or a corresponding vector control. Then, at $48 \mathrm{~h}$ post transfection, cell lysates were prepared and subjected to IP using M2 antiFlag-conjugated beads (Sigma) as described in the manufacturer's instructions. Equivalent immunoprecipitates were subjected to IB with indicated antibodies.

\section{Reverse transcription-quantitative PCR (RT-qPCR) analysis}

Total RNA was isolated using the RNeasy Mini Kit (Qiagen), followed by reverse transcription using the One-Step 
RT-PCR kit (Qiagen) according to the manufacturers' instructions. Quantitative PCR (qPCR) was performed using the QuantiTect SYBR Green PCR kit (Qiagen) according to the manufacturer's instructions. Primer sequences were as follows: HERC3, forward 5'TGTTGGGGATATTGGTCTCTGG-3' and reverse 5'CCC TTG GTG TTC AAA CC ACAT-3'; p63, forward 5'-GTT ATC CGC GCC ATG CCT GTC TAC-3' and reverse 5'-TCC CCT CTA CTC GAA TCA AAT G-3'; GAPDH, forward 5'-AAA ATG GCA GTG CGT TTA G3' and reverse 5'-TTT GAA GGC AGT CTG TCG TA-3'. Control amplification was performed using RNA samples not subjected to the reverse transcription, in parallel, to ensure no contaminating genomic DNA was present.

\section{Lentiviral infection}

An ShRNA library for human E3 ligases, including HERC3, was purchased from Open Biosystems (RHS4896). Lentivirus-based plasmids of pLVX-MM1, pLVX$\Delta$ Np63 $\alpha$, pLKO.1-shp63, pLKO.1-shMM1, and pLKO.1shGFP have been described previously [17]. The 293T cells were co-transfected with lentivirus-based plasmids along with psPAX2 and pMD2.G lentiviral packaging plasmids by LipoPlus. The media were collected and filtered through a $0.45 \mu \mathrm{M}$ filter to remove debris $48 \mathrm{~h}$ later. The lentiviral particles were then concentrated by ultra-centrifugation $\left(20,000 \mathrm{rpm}, 2 \mathrm{~h}\right.$ at $\left.4{ }^{\circ} \mathrm{C}\right)$, resuspended in fresh medium at 4 ${ }^{\circ} \mathrm{C}$ for $24 \mathrm{~h}$, then supplemented with polybrene $(10 \mu \mathrm{g} / \mathrm{ml})$ and used to infect H1299, FaDu, and MCF-10A cells. At 48 $\mathrm{h}$ after infection, the cells were subjected to IB analysis or selected in growth medium supplemented with $2 \mu \mathrm{g} / \mathrm{ml}$ puromycin for 2 days.

\section{SA- $\beta$-gal staining}

For senescence-associated $\beta$-galactosidase (SA- $\beta$-gal) staining, H1299 or MCF-10A cells were infected with lentiviralbased MM1, shHERC3, shp63, or (and) shMM1. Then, $48 \mathrm{~h}$ post infection, the cells were selected in growth medium supplemented with $2 \mu \mathrm{g} / \mathrm{ml}$ puromycin for $48 \mathrm{~h}$. The cells were then subjected to SA- $\beta$-gal staining with SA- $\beta$-Gal Staining Kit (Beyotime, C0602). The percentage of SA- $\beta$-galpositive cells was obtained from three repeat experiments, and $t$-tests were employed for statistical analysis.

\section{Protein stability assay}

Cells were transiently transfected (or infected) with indicated plasmids or small hairpin RNA (shRNA) lentiviruses. At $24 \mathrm{~h}$ post transfection (or infection), cells were treated with CHX at a final concentration of $100 \mu \mathrm{g} / \mathrm{ml}$ for additional $0-5 \mathrm{~h}$. Cells were collected at the indicated time points. Equal amounts of total proteins $(50 \mu \mathrm{g}$ total protein per lane) were subjected to IB analysis. Intensities of bands for MM1 or actin were quantified with Image Lab (Bio$\mathrm{Rad})$. The protein levels of MM1 were normalized with actin, and that at time point $0 \mathrm{~h}$ was set as $100 \%$.

\section{Assays for proteasome-dependent MM1 protein degradation}

H1299 cells with 50\% confluency in 6-well plates were cotransfected with $1 \mu \mathrm{g}$ pCMV2-Flag-MM1 and $1 \mu \mathrm{g}$ pcDNA3.1 or p pCMV-myc-HERC3 by LipoPlus. After 24 $\mathrm{h}$, cells were treated with $20 \mu \mathrm{M}$ MG132 or an equal amount of solvent vehicle DMSO for $6 \mathrm{~h}$ more. Then, cells were collected and lysed with EBC250. Equal amounts of total protein $(50 \mu \mathrm{g}$ total protein per lane) were subjected to IB for HERC3, Myc-tag, p21, MM1, and actin.

\section{Chromatin immunoprecipitation (ChIP)}

ChIP assays were performed with anti-p63 (Cell Signaling Technology, cst-13109), using an Agarose ChIP Kit (Pierce) as described in the manufacturer's instructions. ChIPed DNA was used for qPCR, using 10\% total input sheared DNA as internal controls, with the following primers: site 1, forward 5'-CAG ACT CTT CTT GCT ATG C-3' and reverse 5'- GGA GGT ACG CGG CAG CCG -3' (132 bp); site 2, forward $5^{\prime}$ - CGG CTG CCG CGT ACC TCC $-3^{\prime}$ and reverse 5'- GGT GAC CGA AAG CCT TGG -3' (165 bp); site 3, forward 5'-CAG CGT CAA CGC TCT ATG $-3^{\prime}$ and reverse 5'- GAG GCG GGG CGG CAA GGT C-3' (163 $\mathrm{bp}$ ). The PCR products were subjected to agarose gel electrophoresis.

\section{Results}

\section{E3 ligase HERC3 is involved in $\triangle N p 63 a$-mediated down-regulation of MM1}

Our published data showed that $\Delta \mathrm{Np} 63 \alpha$ promotes proteasome-dependent degradation of MM1 protein in both H1299 and MCF-10A cells [17]; however, the underlying mechanism remains unclear. Ubiquitination mediated by specific E3 ligase is the key step during proteasomal degradation. However, the E3 ligases of MM1 remain unknown. To search specific E3 ligases of MM1 and elucidate the mechanism of how it is down-regulated by $\Delta \mathrm{Np} 63 \alpha$, we carried out screening with an shRNA library for E3 ligases. We transfected H1299 cells with pLKO.1 constructs encoding shRNAs for different E3 ligases, which are transcriptionally controlled by or bind to p63, according to previously published papers or our own unpublished data 

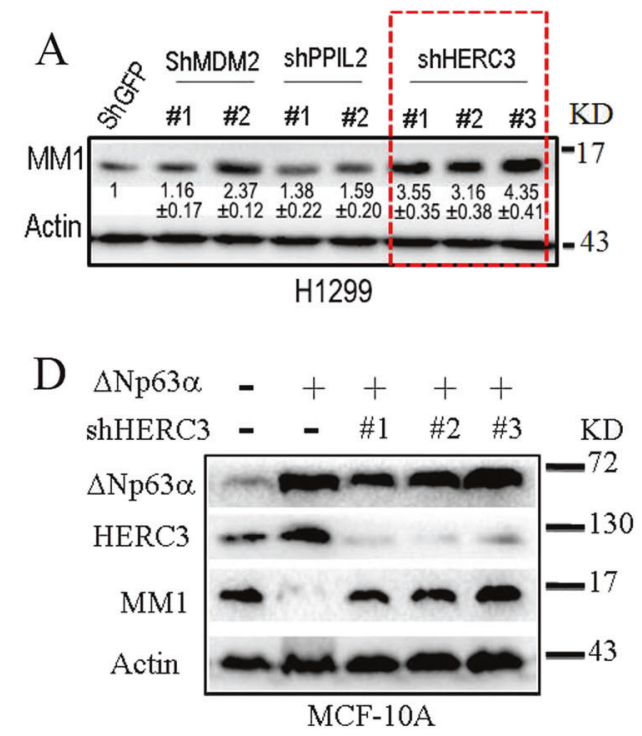

Fig. 1 Knockdown of HERC3 up-regulates MM1 and abrogates $\Delta$ Np63a-mediated down-regulation of MM1. a-c Knockdown of HERC3 induces up-regulation of MM1. H1299 or MCF-10A cells were transfected or infected with shRNA constructs for indicated genes from a pLKO.1 library for E3 ligases, using pLKO.1-shGFP as a control. At $48 \mathrm{~h}$ post transfection/infection, the cells were subjected to IB or RT-qPCR analysis. Intensities of MM1 protein bands were quantified with Image Lab (Bio-Rad, Berkeley, CA, USA) and relative intensities were normalized with actin. Quantification data of IB from

[4, 5, 18, 20-24]. We checked 18 E3 ligases with two or three different shRNAs for each gene. Fortunately, we found that shRNA plasmids for HERC3 (shHERC3) induce a striking up-regulation of endogenous MM1 (Fig. 1a and Figure $\mathrm{S} 1$ in supplementary data). The shRNAs for other E3 ligases, such as MDM2 and HERC1, slightly increase the protein level of MM1, suggesting they may also contribute to proteasomal degradation of MM1 protein. To confirm the effect of HERC3 on MM1 protein levels, we prepared lentiviruses of pLKO.1-shHERC 3 and infected MCF-10A cells with them. The results showed that up-regulation of MM1 induced by depletion of HERC3 also occurs in MCF$10 \mathrm{~A}$ cells (Fig. 1b, c). Further study revealed that knockdown of HERC3 abrogates $\Delta \mathrm{Np} 63 \alpha$-mediated down-regulation of MM1 protein levels (Fig. 1d, e). This suggests that the E3 ligase HERC3 is involved in $\Delta \mathrm{Np} 63 \alpha$-mediated down-regulation of MM1.

\section{HERC3 is a novel E3 ligase of MM1 mediating its ubiquitination and proteasomal degradation}

Our previous study revealed that $\Delta \mathrm{Np} 63 \alpha$ shortens the halflife of MM1 protein [17]. To verify the effect of HERC3 on MM1 protein, we employed a CHX-chase assay to measure the half-life of MM1 protein in the presence or absence of ectopic expression of HERC3. The results demonstrate that, like $\Delta \mathrm{Np} 63 \alpha$ does [17], overexpression of HERC3 shortens
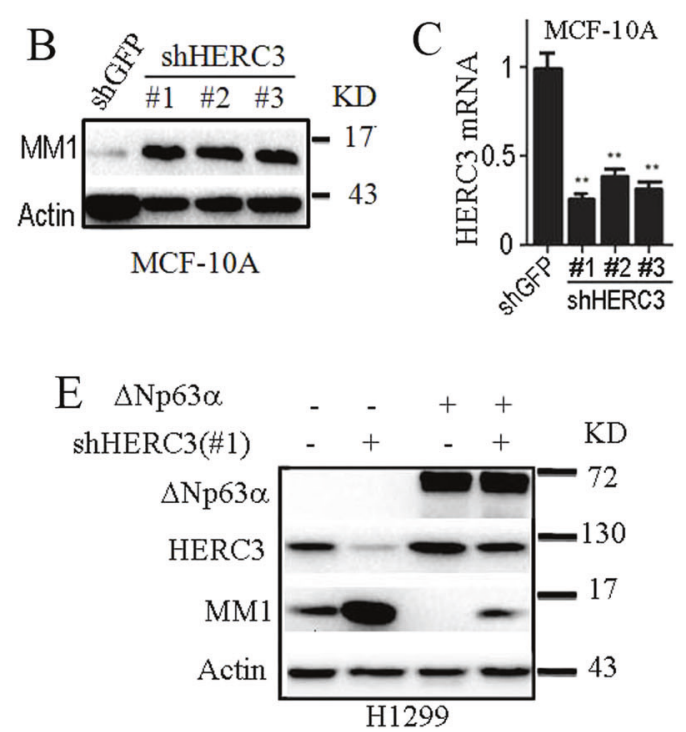

two independent experiments were presented as means $\pm \mathrm{SE}$. The qPCR data were presented as means \pm SE to test the knockdown efficiency of HERC3 (normalized with GAPDH), from three independent experiments performed in triplicate; $* * p<0.01$. d, e Knockdown of HERC3 abrogates $\Delta$ Np63 $\alpha$-mediated down-regulation of MM1. MCF-10A or H1299 cells were infected/transfected with pLVX- $\Delta \mathrm{Np} 63 \alpha$ or (and) pLKO.1-shHERC3. At $48 \mathrm{~h}$ post infection/ transfected, the cells were subjected to IB analysis

the MM1 protein half-life (Fig. 2a, b); on the other hand, knockdown of endogenous HERC3 strikingly extends the protein half-life of MM1 (Fig. 2c, d). The Co-IP assay demonstrates that either ectopically or endogenously expressed proteins of HERC3 and MM1 form a stable complex in H1299 cells (Fig. 2e-g). These results suggest that HERC3 directly binds to MM1 protein and shortens its half-life.

HERC3 is an E3 ligase whose enzymatic activity can be removed by C1018A mutation [19]. To check whether the enzymatic activity of HERC 3 is crucial to the degradation of MM1 protein, we compared the effects of wild-type (Wt HERC3) and C1018A mutant HERC3 (Mut HERC3) on MM1 protein levels. The results demonstrate that C1018A mutation almost completely abrogates HERC3 ability to down-regulate MM1 (Fig. 2h). To know if this regulation is dependent on proteasomal degradation, we treated cells with proteasome inhibitor MG132. The results demonstrate that $\mathrm{p} 21$, which is a well-known protein undergoing proteasomal degradation, is significantly up-regulated by MG132, indicating the effectiveness of this drug; and MG132 obviously rescues the down-regulation of MM1 mediated by HERC3 (Fig. 2i). On the other hand, the ubiquitination assay demonstrates that HERC3 dramatically increases, while knockdown of HERC3 reduces, polyubiquitination modification of MM1 (Fig. 2j). These data indicate that HERC3 is a novel E3 ligase of MM1, which mediates its ubiquitination and proteasomal degradation. 

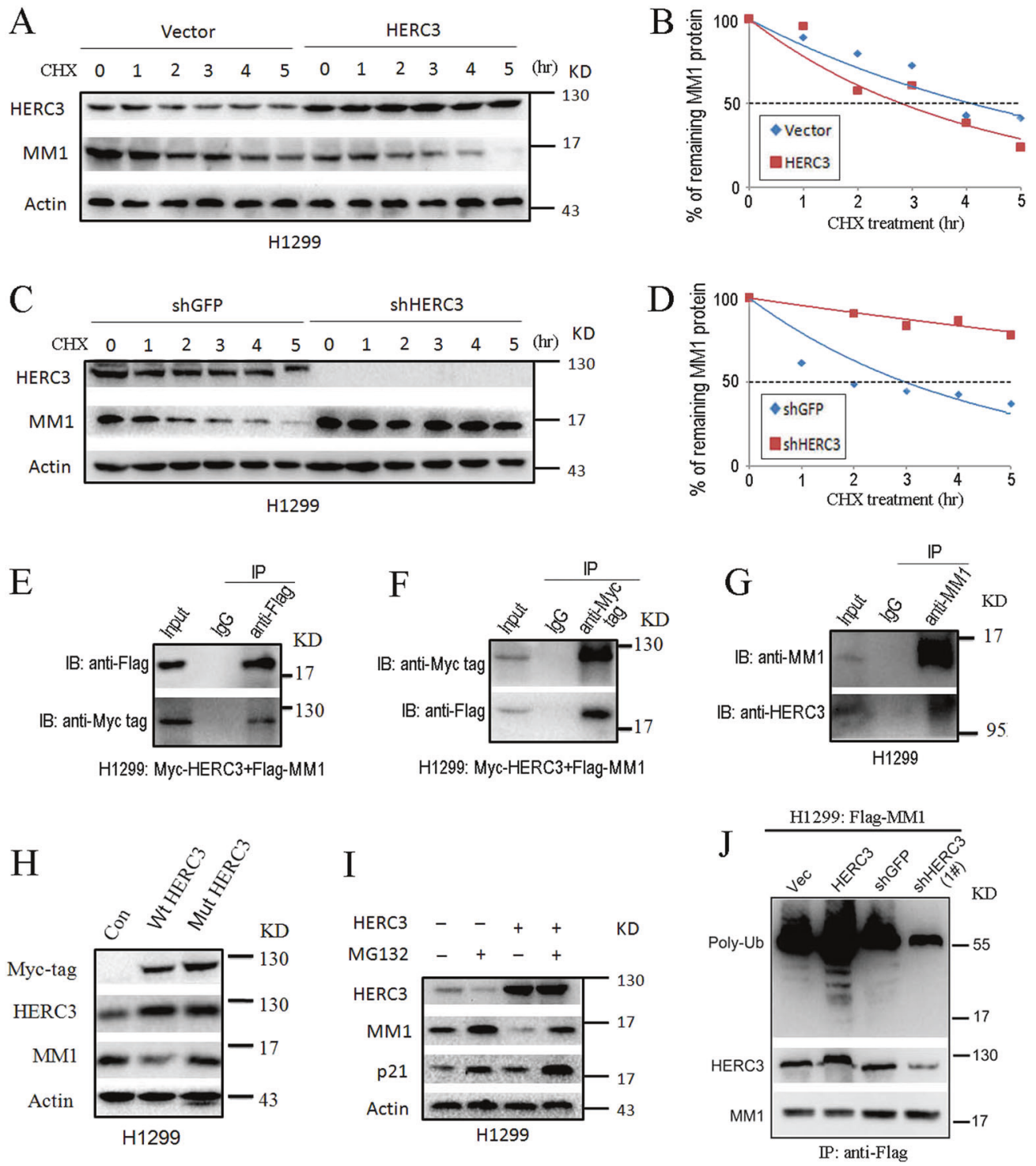

Fig. 2 HERC3 is a novel E3 ligase of MM1 mediating its ubiquitination and proteasomal degradation. a, $\mathbf{c}$ The half-life of MM1 protein is shortened by HERC3. H1299 cells were transfected with HERC3 or vector control. At $24 \mathrm{~h}$ post transfection, cells were treated with 100 $\mu \mathrm{g} / \mathrm{ml}$ cycloheximide (CHX) for indicated time intervals, followed by IB analysis. b, d Quantification results of $(\mathbf{a}, \mathbf{c})$ respectively. Percentages of MM1 protein were normalized with actin, and the value at time point $0 \mathrm{~h}$ was set as $100 \%$. e, f Exogenous HERC3 and MM1 proteins form stable complexes. Myc-tagged HERC 3 and Flag-tagged MM1 were transiently overexpressed in $\mathrm{H} 1299$ cells. At $48 \mathrm{~h}$ post transfection, cells were harvested and cell lysates were subjected to IP with antibody to Flag or Myc-tag, using normal mouse $\operatorname{IgG}(\operatorname{IgG})$ as a control. g Endogenous HERC3 and MM1 proteins form stable complexes. Cell lysate of $\mathrm{H} 1299$ cells was subjected to IP with antibody to MM1, using normal mouse IgG as a control. The immunoprecipitates were analyzed by IB with indicated antibodies. Whole cell lysates

\section{$\triangle$ Np63a transactivates HERC3 gene to increase its expression}

$\Delta \mathrm{Np} 63 \alpha$ functions as a transcription factor that exerts its transactivity via binding to promoter regions of its target were used as input controls. h HERC3 down-regulates MM1 dependently of its E3 ligase activity. H1299 cells were transfected with Myctagged wild-type HERC3 (Wt HERC3) or its C1018A mutant (Mut HERC3), which loses E3 ligase activity, using their empty vector pCMV as a control (Con). At $48 \mathrm{~h}$ post transfection, cells were lysed and subjected to IB analysis. i HERC3 down-regulates MM1 dependently of proteasome. H1299 cells were transfected with HERC3 or its vector control. At $24 \mathrm{~h}$ post transfection, cells were treated with $20 \mu \mathrm{M}$ MG132 or an equal volume of solvent vehicle DMSO for additional 6 h. Cells were then harvested and subjected to IB analysis. j HERC3 mediates poly-ubiquitination of MM1. H1299 cells were transfected with Flag-tagged MM1 and ubiquitin, plus HERC3, shHERC3 (1\#) or their vector controls. At $48 \mathrm{~h}$ post transfection, cells were lysed and subjected to IP with anti-Flag-conjugated beads. The immunoprecipitates were subjected to IB analysis for ubiquitinated MM1 with antiubiquitin or for indicated proteins

genes. To check whether down-regulation of MM1 induced by $\Delta \mathrm{Np} 63 \alpha$ depends on its ability to transactivate downstream genes, we used a plasmid of $\Delta \mathrm{Np} 63 \alpha$ with a C306R point mutation, which fails to bind to $\mathrm{p} 63$ response elements [9]. The results demonstrate that, compared to wild-type 
Fig. $3 \Delta \mathrm{Np} 63 \alpha$ transactivates HERC 3 gene to increase its expression. a C306R mutant $\Delta \mathrm{Np} 63 \alpha$ fails to down-regulate MM1. Vector control, $\Delta \mathrm{Np} 63 \alpha$, or $\Delta \mathrm{Np} 63 \alpha(\mathrm{C} 306 \mathrm{R})$ plasmid was transfected into H1299 cells. After $48 \mathrm{~h}$, cells were lysed and subjected to IB with indicated antibodies. b-f Overexpression of wild-type $\Delta \mathrm{Np} 63 \alpha$, but not its C306R mutant, enhances HERC3 mRNA and protein levels. H1299 or MCF-10A cells were transiently overexpressed with wild-type $\Delta \mathrm{Np} 63 \alpha$ or its C306R mutant, which loses the ability to transactivate its downstream genes. At $48 \mathrm{~h}$ post transfection/ infection, cells were harvested and subjected to IB or RT-qPCR analysis. The $\mathrm{qPCR}$ data are presented as means $\pm \mathrm{SE}$ to measure mRNA levels of HERC3 (normalized with GAPDH), from three independent experiments performed in triplicate; ${ }^{*} p<$ 0.01. g Promoter region of HERC 3 gene contains three potential p63 binding sites (highlighted sequences). h p63 directly binds to sites 1 and 3 within HERC3 promoter. Sheared genomic DNA from MCF-10A cells was subjected to ChIP assay using anti-p63 or normal mouse IgG (IgG). The immunoprecipitates or sheared genomic DNA (gDNA) were subjected to PCR amplification to detect fragments respectively containing the three sites
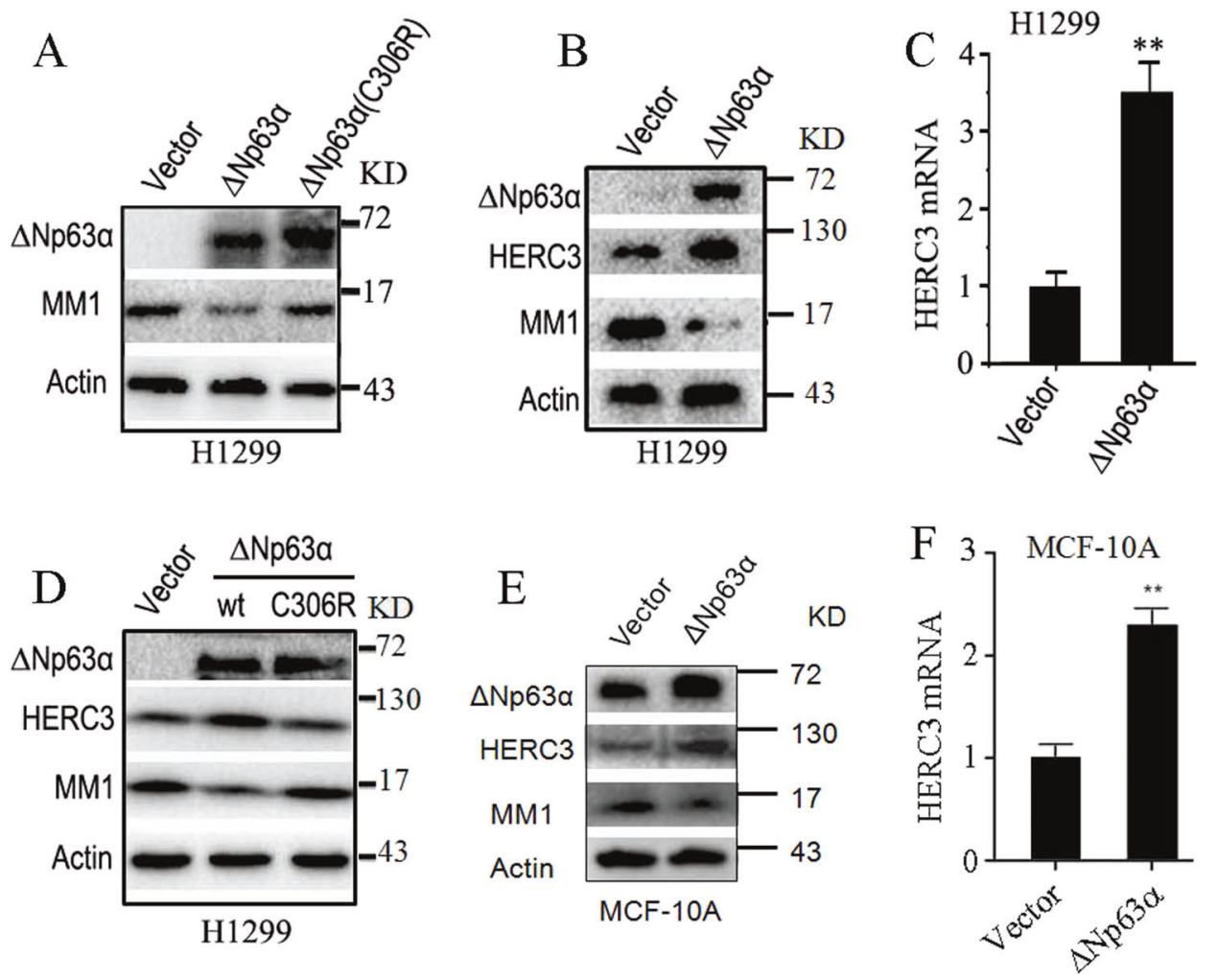

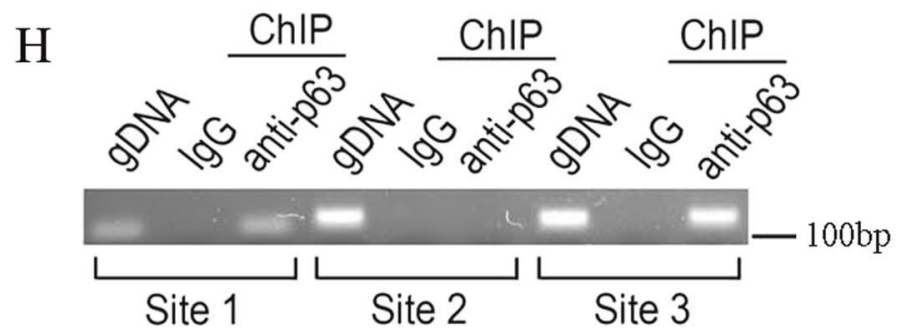

$\Delta \mathrm{Np} 63 \alpha$, the C306R mutant fails to down-regulate MM1 (Fig. 3a). This suggests that $\Delta \mathrm{Np} 63 \alpha$ promotes MM1 degradation via regulation of certain target genes.

Since Fig. 1d, e demonstrates that HERC3 is involved in $\Delta \mathrm{Np} 63 \alpha$-mediated down-regulation of MM1, we wondered if the expression of HERC 3 can be stimulated by $\Delta \mathrm{Np} 63 \alpha$. Our results show that overexpression of $\Delta \mathrm{Np} 63 \alpha$ in $\mathrm{H} 1299$ cells significantly increases expression of HERC3 (Fig. 3b). TAp63 $\alpha$, which was previously reported to down-regulate MM1 like $\Delta \mathrm{Np} 63 \alpha$ does, can also increase HERC3 protein 
Fig. 4 Overexpression of MM1 prevents cell proliferation and induces cell senescence. MCF10A or H1299 cells were infected/transfected with MM1 or vector control. At $48 \mathrm{~h}$ post infected/transfected, cells were selected with $2 \mu \mathrm{M}$ puromycin for 2 days. The surviving cells were split into 12-well plates for MTS assay at indicated time points (a, e), SA- $\beta-$ Gal staining $(\mathbf{b}, \mathbf{c}, \mathbf{f}, \mathbf{g})$, or IB analysis $(\mathbf{d}, \mathbf{h})$. Data are presented as means \pm SE from three independent experiments performed in triplicate; $* * p<0.01 ; * * * p<$ 0.001
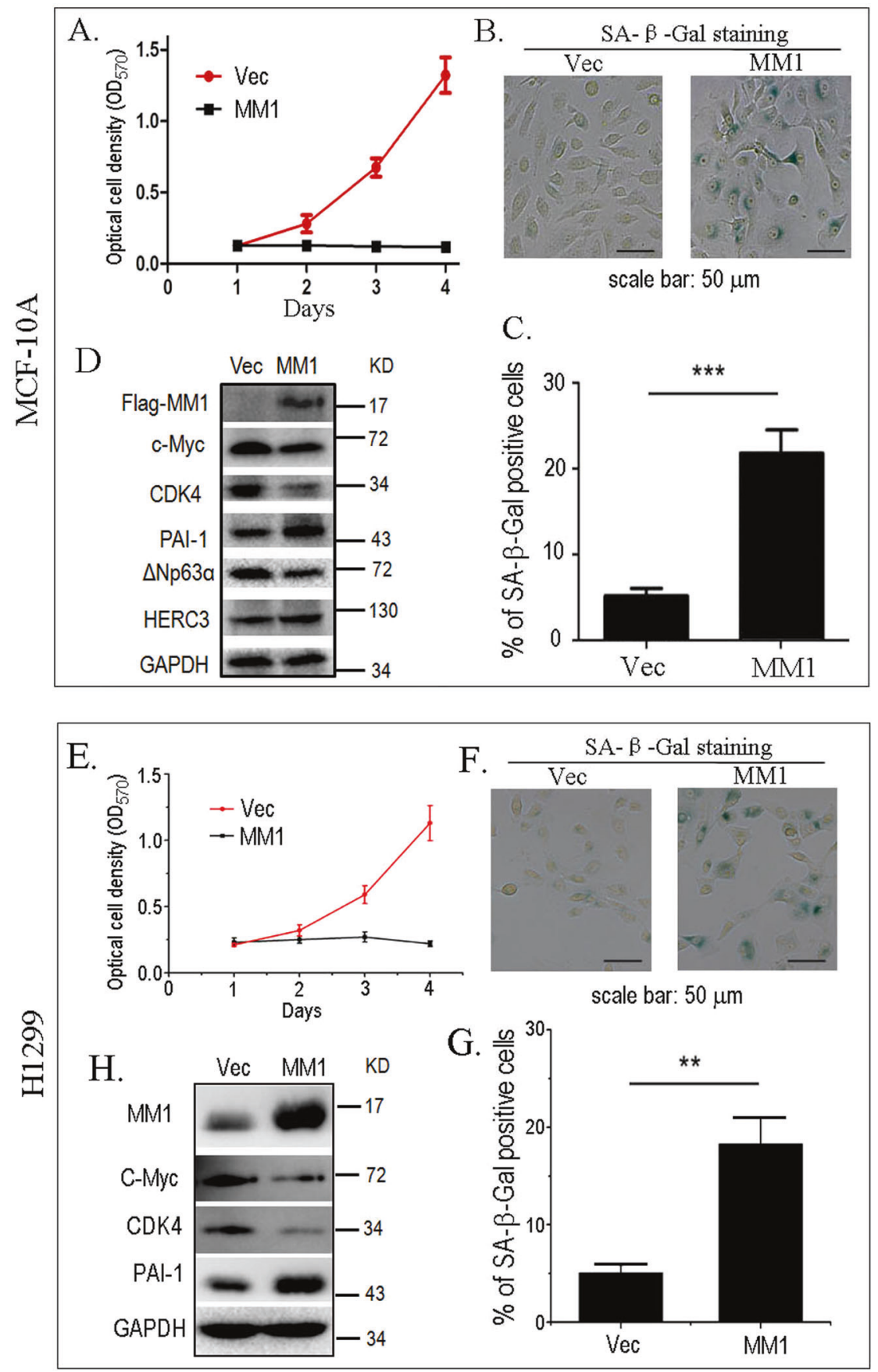

levels (Figure S2A in supplementary data). Since $\Delta \mathrm{Np} 63 \alpha$ and TAp63 $\alpha$ are both transcription factors, we employed the RT-qPCR assay to investigate if this up-regulation of HERC3 occurs at the messenger RNA (mRNA) level. The results reveal that the HERC 3 mRNA level is significantly elevated by $\Delta \mathrm{Np} 63 \alpha$ (Fig. 3c). However, the C306R mutant $\Delta \mathrm{Np} 63 \alpha$, which loses the ability to bind to p63 response elements to transactivate the downstream genes, fails to upregulate HERC3 (Fig. 3d). This $\Delta \mathrm{Np} 63 \alpha$-induced expression of HERC3 also occurs in MCF-10A cells (Fig. 3e, f).
On the other hand, knockdown of p63 in MCF-10A or $\mathrm{FaDu}$ cells, which predominantly express $\Delta \mathrm{Np} 63 \alpha$ isoform, results in a striking down-regulation of HERC3 (Figures S2B, C in supplementary data). As a transcription factor, $\Delta \mathrm{Np} 63 \alpha$ prefers to recognize and bind to a consensus sequence CNNGNNNNNNCNNG in the promoter regions of various genes to stimulate their transcription [25]. It was reported that $\Delta \mathrm{Np} 63 \alpha$ may bind to promoter of HERC3 gene [4]. Our analysis reveals that there are three potential binding sites of $\Delta \mathrm{Np} 63 \alpha$ in the HERC3 promoter 
Fig. 5 Ablation of MM1 partially rescues cell senescence induced by $\Delta \mathrm{Np} 63 \alpha$ knockdown. MCF-10A cells were infected with lentivirusbased shRNAs for GFP (as a control), p63, or (and) MM1. At $48 \mathrm{~h}$ post infection, cells were selected with $2 \mu \mathrm{M}$ puromycin for 2 days. The surviving cells were subjected to SA- $\beta$-Gal staining (a), IB analysis (b), or MTS assay (c). Data are presented as means \pm SE from three independent experiments performed in triplicate; ${ }^{* * *} p<$ 0.001

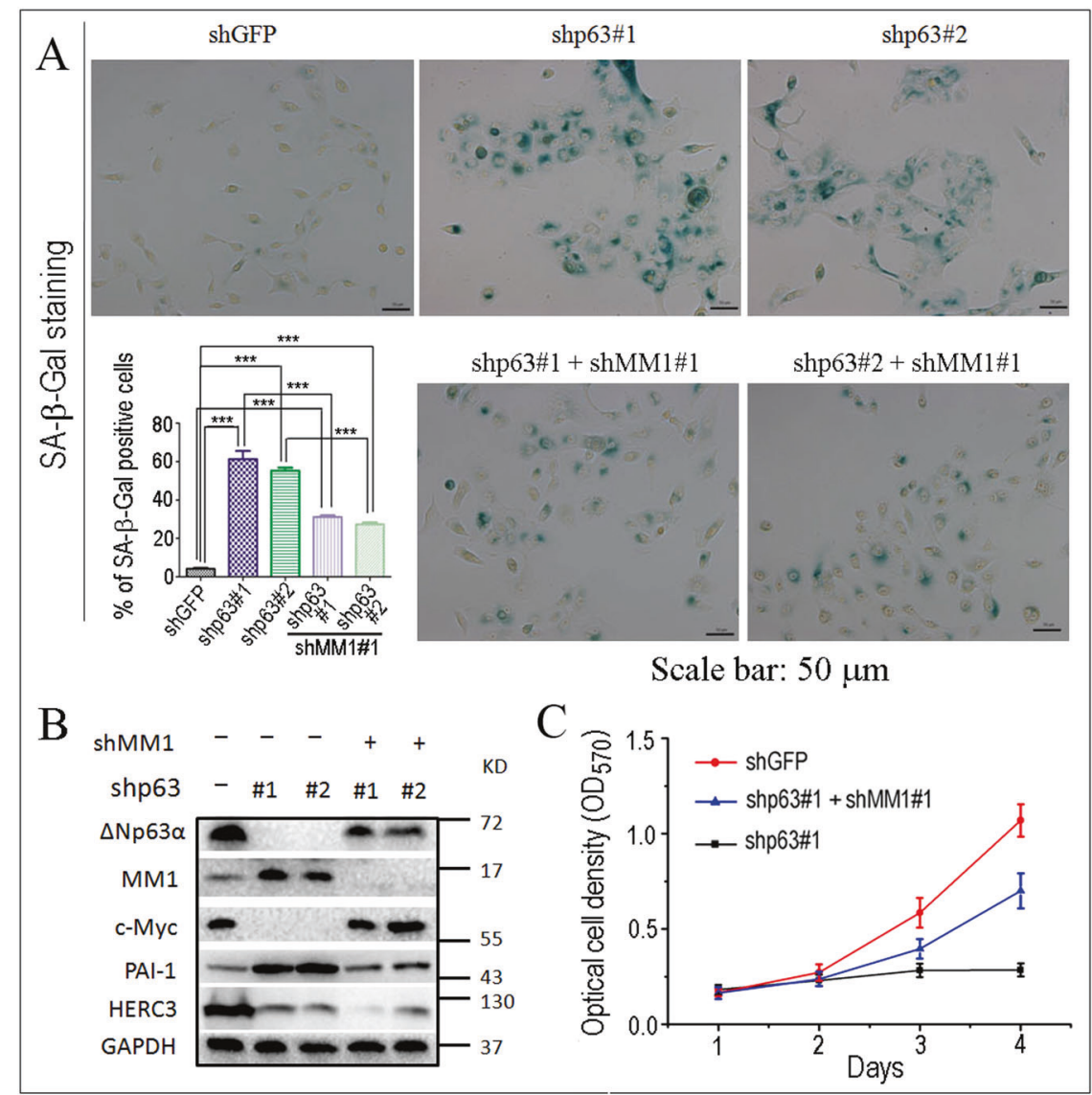

MCF-10A
(Fig. 3g). To further validate the direct regulation of p63 on HERC3 transcription, we employed a ChIP assay. The results demonstrate that fragments containing either site 1 or site 3 can be detected in ChIPed products from sheared MCF-10A genomic DNA with anti-p63 (Fig. 3h). These results suggest that $\triangle \mathrm{Np} 63 \alpha$ transactivates the HERC 3 gene to increase its expression.

\section{MM1 induces proliferative cell senescence}

In our previous study, we found that MM1 can modulate cMyc transactivity and cell cycle progression [17]. To further investigate the biological functions of MM1, we overexpressed it in MCF-10A cells and found that cell proliferation is dramatically repressed (Fig. 4a). SA- $\beta-G a l$ staining demonstrates that MM1 overexpression significantly increases the percentage of SA- $\beta$-Gal-positive cells, which is a hallmark of cell senescence (Fig. 4b, c). The IB analysis demonstrates that c-Myc and its downstream target CDK4 are dramatically down-regulated by MM1, while the protein level of cellular senescence marker PAI-1 is elevated (Fig. 4d). These data suggest that MM1mediated repression of c-Myc can inhibit cell proliferation and induce cell senescence. Intriguingly, we found that
$\Delta$ Np63 $\alpha$ protein level was down-regulated in cells transfected with MM1 (Fig. 4d). This finding was reproducible in both MCF-10A and FaDu cells (Figures S3A, B in supplementary data). On the other hand, knockdown of MM1 results in up-regulation of endogenous $\Delta \mathrm{Np} 63 \alpha$ protein (Figures S3C, D). Further study demonstrated that inhibition of proteasome with MG132 fails to rescue MM1mediated down-regulation of $\Delta \mathrm{Np} 63 \alpha$ (Figure S3E), while RT-qPCR results showed that MM1 induces a significant decrease in $\triangle$ Np63 $\alpha$ mRNA level (Figure S3F). These data suggest that MM1 down-regulates $\Delta \mathrm{Np} 63 \alpha$ at the mRNA level.

To further investigate the effects of MM1 on cell senescence, we overexpressed MM1 in H1299 cells. As shown in Fig. 4e-h, our results reveal that, like in MCF10A, MM1 also represses cell proliferation as well as expression of c-Myc and CDK4 in H1299 cells; the increases in SA- $\beta$-Gal and PAI-1 demonstrate MM1induced H1299 cell senescence. Since H1299 cells do not express endogenous p63 proteins, cell senescence induced by MM1 might be, at least to some extent, independent of its negative regulation on p63. Taken together, our results show that MM1 induces proliferative cell senescence. 
Fig. 6 Ablation of HERC3 induces cell senescence, which can be strikingly rescued by MM1 depletion. MCF-10A or H1299 cells were infected/ transfected with shRNAs for GFP (as a control), HERC3, or (and) MM1. At $48 \mathrm{~h}$ post infection/transfection, cells were selected with $2 \mu \mathrm{M}$ puromycin for 2 days. The surviving cells were subjected to SA- $\beta$-Gal staining $(\mathbf{a}, \mathbf{b}, \mathbf{d}, \mathbf{e})$ or IB analysis $(\mathbf{c}, \mathbf{f})$. Data are presented as means $\pm \mathrm{SE}$ from three independent experiments performed in triplicate; $* * * p<$ 0.001
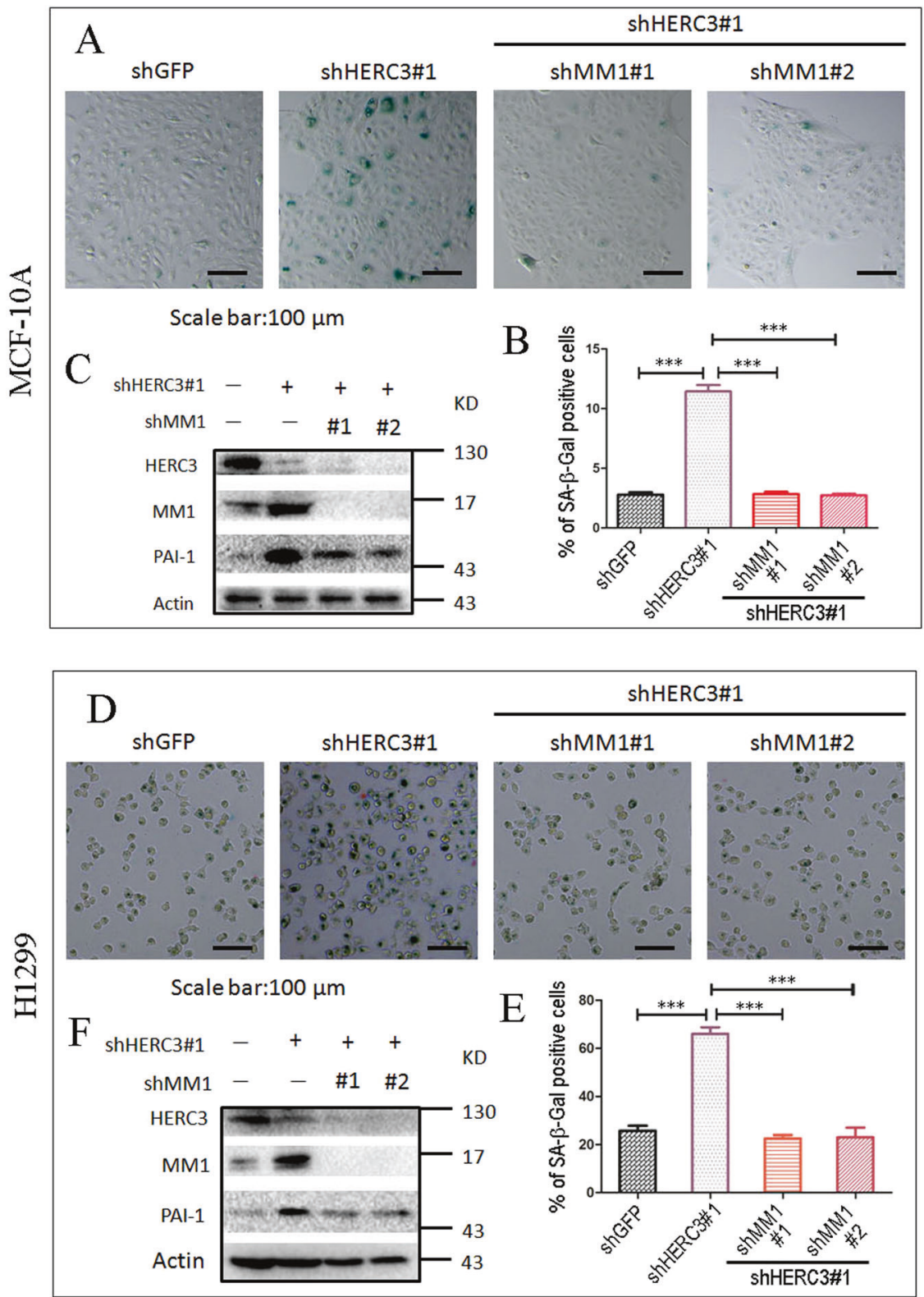

\section{Depletion of MM1 partially rescues cell senescence induced by $\Delta$ Np63a knockdown}

It was reported that deficiency of p63, particularly its predominant isoform $\Delta \mathrm{Np} 63 \alpha$, can trigger a cellular senescence program [26]. To check whether MM1 is involved in $\Delta$ Np63 $\alpha$-regulated cell senescence, we knocked down endogenous $\Delta \mathrm{Np} 63 \alpha$ and MM1 with lentivirus-based shRNAs. The results demonstrate that knockdown of $\Delta \mathrm{Np} 63 \alpha$, which is the predominant isoform of p63 expressed in MCF-10A cells, induces a remarkable increase in the percentage of SA- $\beta$-Gal-positive cells, which can be partially, but significantly, rescued by simultaneous knockdown of MM1 (Fig. 5a). The IB analysis confirms the alteration and restoration of both the $\Delta \mathrm{Np} 63 \alpha / \mathrm{MM} 1 / \mathrm{c}-\mathrm{Myc}$ axis and senescence marker PAI-1 (Fig. 5b). Being consistent with the above-mentioned finding that MM1 inhibits $\Delta \mathrm{Np} 63 \alpha$ (Fig. $4 \mathrm{~d}$ and S3), simultaneous knockdown of MM1 can restore the expression of $\Delta \mathrm{Np} 63 \alpha$ in p63knockdown cells (Fig. 5b, lanes 4 and 5 vs lanes 2 and 3). On the other hand, ablation of $\Delta \mathrm{Np} 63 \alpha$ induces a striking repression of cell proliferation, which can be partially rescued by simultaneous knockdown of MM1 (Fig. 5c). These results suggest that elevated MM1 protein levels and subsequent repression of c-Myc, to some extent, accounts for cell senescence induced by deficiency of $\Delta \mathrm{Np} 63 \alpha$. 
Fig. 7 Oncomine analyses of p63, HERC3, MM1, and c-Myc genes in invasive breast carcinoma. Box plots represent the expression of indicated genes in invasive breast carcinoma samples (Finak Breast dataset)
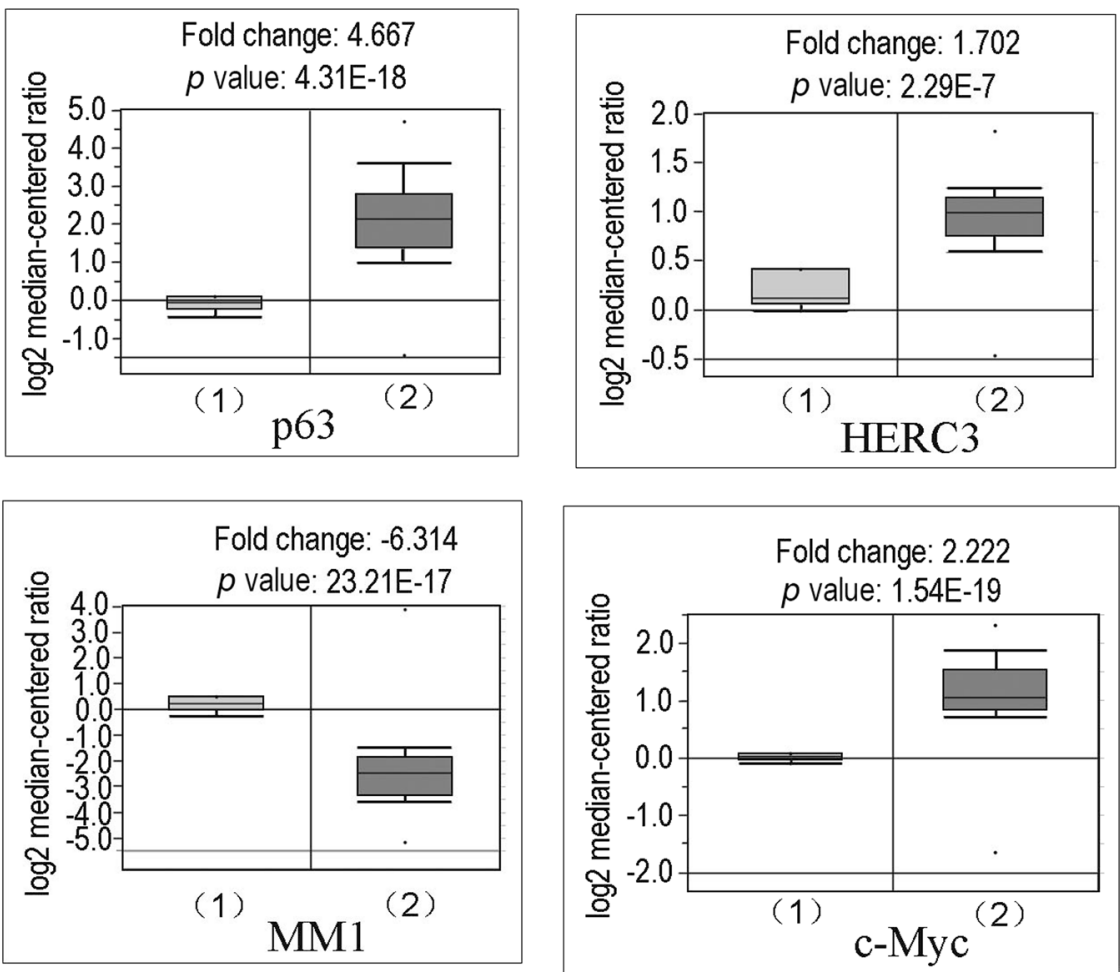

(1) Breast $(n=6)$; (2) Invasive Breast Carcinoma ( $n=53)$

\section{Ablation of HERC3 induces cell senescence, which can be strikingly rescued by MM1 depletion}

Since Figs. 1-3 show that HERC3 is a key regulator of the $\Delta \mathrm{Np} 63 \alpha / \mathrm{MM} 1 / \mathrm{c}-\mathrm{Myc}$ axis, we wondered if it plays some roles in cell senescence. To this end, we knocked down HERC3 in either MCF-10A or H1299 cells and performed SA- $\beta-\mathrm{Gal}$ assays. The results demonstrate that knockdown of HERC3 with three different shRNA constructs significantly up-regulates the MM1 protein level and increases the percentage of SA- $\beta$-Gal-positive cells in either MCF-10A or H1299 cells (Figure S4). To evaluate the roles of MM1 in cell senescence induced by HERC3 knockdown, we simultaneously knocked down MM1. The results demonstrate that knockdown of MM1 can significantly rescue cell senescence induced by HERC3 ablation (Fig. 6). In combination with the abovementioned observation that MM1 represses c-Myc and induces cell senescence, these data indicate that HERC3 can modulate cell senescence via regulating MM1 protein levels.

\section{The $\Delta \mathrm{Np} 63 \mathrm{a} / \mathrm{HERC} / \mathrm{MM} 1 / \mathrm{c}-\mathrm{Myc}$ axis is up-regulated in invasive breast carcinoma}

Low incidence of cell senescence is a major property of cancers, endowing them with malignant proliferation properties. Since Figs. $4-6$ demonstrate that the $\Delta$ Np $63 \alpha /$
HERC3/MM1 axis plays a key role in the regulation of proliferative cell senescence in MCF-10A human immortalized mammary epithelial cells, we evaluated the status of this axis in breast cancers. As shown in Fig. 7, expressions of p63, HERC3, and c-Myc are significantly up-regulated in invasive breast carcinoma, while MM1 is markedly downregulated. These results indicate that the $\Delta \mathrm{Np} 63 \alpha / \mathrm{HERC} 3 /$ MM1/c-Myc axis may play some roles in the tumorigenesis of invasive breast carcinoma.

\section{Discussion}

Both p63 and c-Myc are important transcription factors playing key roles in cell cycle progress and tumorigenesis via regulating the expression of a range of downstream genes [1-3, 14-16]. It has been reported that p63 positively regulates c-Myc via Wnt/ $\beta$-catenin and Notch signaling pathways, governing keratinocyte proliferation or differentiation [27]. Our previous data show that $p 63 \alpha$ promotes protein degradation of c-Myc modulator MM1, thereby depressing c-Myc and consequently regulating cell cycle progression [17]. To elucidate the underlying mechanism of how $\mathrm{p} 63 \alpha$ facilitates proteasome-dependent degradation of MM1, we performed a screening to search for the specific E3 ubiquitin ligase targeting MM1 to proteasomal degradation. We found that HERC3 mediates poly-ubiquitination of MM1 protein and accelerates its proteasome-dependent 
degradation, suggesting that HERC3 is a novel E3 ubiquitin ligase for MM1 protein. On the other hand, HERC3 knockdown abrogates $\Delta$ Np63 $\alpha$-induced MM1 down-regulation, suggesting it is a key mediator in this process. Additionally, we identified HERC3 as a novel downstream target gene of $\Delta \mathrm{Np} 63 \alpha$, which positively regulates HERC3 mRNA levels. Considering the fact that we only checked a small fraction of the whole library of E3 ligases, and that shHERC3 is simply the most robust one in up-regulating MM1 protein levels, we do not rule out the possibility that there may be other E3 ligases involved in this $\Delta \mathrm{Np} 63 \alpha-$ induced MM1 down-regulation. Collectively, our data illuminate a novel $\Delta \mathrm{Np} 63 \alpha / \mathrm{HERC} 3 / \mathrm{MM} 1 / \mathrm{c}-\mathrm{Myc}$ axis: $\Delta \mathrm{Np} 63 \alpha$ transactivates E3 ligase HERC3, which mediates ubiquitination of MM1 and subsequently down-regulates it via accelerating its degradation. According to data from other groups, MM1 may negatively regulate c-Myc via either inhibiting its transactivity or facilitating its degradation [28-30].

As a modulator of c-Myc, which controls approximately $15 \%$ of genes ranging from Drosophila to humans and is activated in more than $20 \%$ of malignant tumors [31, 32], MM1 shows features of a tumor suppressor. The research group of Ariga [33] found that in about $50-60 \%$ of leukemia/lymphoma cells, and in more than $75 \%$ of squamous cell carcinoma of tongue cancer, MM1 is mutated and fails to repress c-Myc transactivity. However, how MM1 is regulated remains unknown. Our identification of HERC3 as a novel E3 ligase that targets MM1 to proteasomal degradation helps our understanding of the protein stability regulation of this important co-factor.

Despite the fact that HERC3 is highly homologous to other members of the HERC family and is found to associate with ubiquitin [34], no evidence so far shows that HERC 3 functions as an E3 ubiquitin ligase targeting proteins to proteasome-mediated degradation $[35,36]$. Hochrainer et al. [19] reported that HERC3 provides a link between nuclear factor- $\mathrm{kB}$ RelA and proteasome to facilitate degradation of RelA. However, this process is independent of the enzymatic activity of HERC3 [19]. Our data, for the first time, prove that HERC 3 can mediate protein ubiquitination and thereby accelerate proteasome-dependent protein degradation. Additionally, we found that $\Delta \mathrm{Np} 63 \alpha$ can transcriptionally up-regulate HERC3, helping us to understand the regulation of this E3 ligase, whose mutation has been found to associate with colorectal and gastric carcinomas [37].

By halting cell proliferation, cell senescence plays key roles either against tumorigenesis or in leading to organismal aging $[38,39]$. Both $\Delta \mathrm{Np} 63 \alpha$ and c-Myc are key transcription factors promoting cell proliferation and opposing cell senescence via enhancing E2F activity or maintaining telomeres through multiple pathways
$[15,16,20,26,40,41]$. In the present study, we show that $\Delta \mathrm{Np} 63 \alpha$ inhibits proliferative cell senescence via positively regulating c-Myc: $\Delta \mathrm{Np} 63 \alpha$ may up-regulate c-Myc via either our newly found $\Delta \mathrm{Np} 63 \alpha / \mathrm{HERC} 3 / \mathrm{MM} 1 / \mathrm{c}-\mathrm{Myc}$ axis or the previously reported Wnt/ $\beta$-catenin and Notch signaling pathways [27]. The partial rescue effect of MM1 ablation on cell senescence induced by $\Delta \mathrm{Np} 63 \alpha$ deficiency suggests that the $\Delta \mathrm{Np} 63 \alpha / \mathrm{HERC} 3 / \mathrm{MM} 1 / \mathrm{c}-\mathrm{Myc}$ axis accounts for $\Delta \mathrm{Np} 63 \alpha$ regulation of cell senescence to some extent. $\Delta \mathrm{Np} 63 \alpha$ may also bypass this axis and directly modulate some cell cycle regulators to inhibit senescence. The Oncomine analysis (Fig. 7) showed that $\Delta \mathrm{Np} 63 \alpha$, HERC3, and c-Myc are up-regulated in invasive breast carcinoma, indicating that activation of this axis may play some roles in tumorigenesis. Of note, the Oncomine analysis reveals only mRNA levels. Our hypothesis of the $\Delta \mathrm{Np} 63 \alpha / \mathrm{HERC} 3 / \mathrm{MM} 1 / \mathrm{c}-\mathrm{Myc}$ axis assumes that activation of $\Delta \mathrm{Np} 63 \alpha$ leads to up-regulation of HERC 3 and c-Myc at the mRNA level, as well as down-regulation of MM1 at the protein level. Down-regulation of MM1 mRNA shown in the Oncomine results indicates that other mechanisms may be involved in the regulation of MM1 and c-Myc during tumorigenesis of invasive breast carcinoma. Additionally, the fact that MM1 negatively regulates transcription of $\Delta \mathrm{Np} 63 \alpha$ (Figure S3) suggests a feedback loop between them.

Taken together, our work elucidates a novel pathway in which $\Delta \mathrm{Np} 63 \alpha$ positively regulates c-Myc, and strongly implicates its role in cell senescence and tumorigenesis.

Acknowledgements This work was supported by the National Natural Science Foundation of China (\#91749121, \#31671423 to CL and \#81330054 to Z-XX) and the Science and Technology Department of Sichuan Province (\#2016JY0152 to CL). We thank Dr. Karin Hochrainer (Feil Family Brain and Mind Research Institute, Weill Cornell Medicine) for her generous gift of HERC3 and its C1018A mutant plasmids.

\section{Compliance with ethical standards}

Conflict of interest The authors declare that they have no conflict of interest.

\section{References}

1. Yang A, Kaghad M, Wang Y, Gillett E, Fleming MD, Dotsch V, et al. p63, a p53 homolog at 3q27-29, encodes multiple products with transactivating, death-inducing, and dominant-negative activities. Mol Cell. 1998;2:305-16.

2. Yang A, Schweitzer R, Sun D, Kaghad M, Walker N, Bronson RT, et al. p63 is essential for regenerative proliferation in limb, craniofacial and epithelial development. Nature. 1999;398:714-8.

3. Mills AA, Zheng B, Wang XJ, Vogel H, Roop DR, Bradley A. p63 is a p53 homologue required for limb and epidermal morphogenesis. Nature. 1999;398:708-13.

4. Kouwenhoven EN, Oti M, Niehues $\mathrm{H}$, van Heeringen SJ, Schalkwijk J, Stunnenberg HG, et al. Transcription factor p63 
bookmarks and regulates dynamic enhancers during epidermal differentiation. EMBO Rep. 2015;16:863-78.

5. Kouwenhoven EN, van Heeringen SJ, Tena JJ, Oti M, Dutilh BE, Alonso ME, et al. Genome-wide profiling of p63 DNA-binding sites identifies an element that regulates gene expression during limb development in the 7q21 SHFM1 locus. PLoS Genet. 2010;6:e1001065.

6. Chakravarti D, Su X, Cho MS, Bui NH, Coarfa C, Venkatanarayan $\mathrm{A}$, et al. Induced multipotency in adult keratinocytes through down-regulation of DeltaNp63 or DGCR8. Proc Natl Acad Sci USA. 2014;111:E572-81.

7. Mangiulli M, Valletti A, Caratozzolo MF, Tullo A, Sbisa E, Pesole G, et al. Identification and functional characterization of two new transcriptional variants of the human p63 gene. Nucleic Acids Res. 2009;37:6092-104.

8. Westfall MD, Mays DJ, Sniezek JC, Pietenpol JA. The Delta Np63 alpha phosphoprotein binds the p21 and 14-3-3 sigma promoters in vivo and has transcriptional repressor activity that is reduced by Hay-Wells syndrome-derived mutations. Mol Cell Biol. 2003;23:2264-76.

9. Bergholz J, Zhang Y, Wu J, Meng L, Walsh EM, Rai A, et al. DeltaNp63alpha regulates Erk signaling via MKP3 to inhibit cancer metastasis. Oncogene. 2014;33:212-24.

10. Candi E, Rufini A, Terrinoni A, Dinsdale D, Ranalli M, Paradisi A, et al. Differential roles of p63 isoforms in epidermal development: selective genetic complementation in p63 null mice. Cell Death Differ. 2006;13:1037-47.

11. Celardo I, Grespi F, Antonov A, Bernassola F, Garabadgiu AV, Melino G, et al. Caspase-1 is a novel target of p63 in tumor suppression. Cell Death Dis. 2013;4:e645.

12. Ihrie RA, Marques MR, Nguyen BT, Horner JS, Papazoglu C, Bronson RT, et al. Perp is a p63-regulated gene essential for epithelial integrity. Cell . 2005;120:843-56.

13. Murray-Zmijewski F, Lane DP, Bourdon JC. p53/p63/p73 isoforms: an orchestra of isoforms to harmonise cell differentiation and response to stress. Cell Death Differ. 2006;13:962-72.

14. Adachi S, Obaya AJ, Han Z, Ramos-Desimone N, Wyche JH, Sedivy JM. c-Myc is necessary for DNA damage-induced apoptosis in the $\mathrm{G}(2)$ phase of the cell cycle. Mol Cell Biol. 2001;21:4929-37.

15. Dang CV. MYC on the path to cancer. Cell . 2012;149:22-35.

16. Wu CH, van Riggelen J, Yetil A, Fan AC, Bachireddy P, Felsher DW. Cellular senescence is an important mechanism of tumor regression upon c-Myc inactivation. Proc Natl Acad Sci USA. 2007;104:13028-33.

17. Han A, Li J, Li Y, Wang Y, Bergholz J, Zhang Y, et al. p63alpha modulates c-Myc activity via direct interaction and regulation of MM1 protein stability. Oncotarget. 2016;7:44277-87.

18. Li X, Chen J, Yi Y, Li C, Zhang Y. DNA damage down-regulates DeltaNp63alpha and induces apoptosis independent of wild type p53. Biochem Biophys Res Commun. 2012;423:338-43.

19. Hochrainer K, Pejanovic N, Olaseun VA, Zhang S, Iadecola C, Anrather J. The ubiquitin ligase HERC3 attenuates NF-kappaBdependent transcription independently of its enzymatic activity by delivering the RelA subunit for degradation. Nucleic Acids Res. 2015;43:9889-904.

20. Li Y, Zhou Z, Chen C. WW domain-containing E3 ubiquitin protein ligase 1 targets p63 transcription factor for ubiquitinmediated proteasomal degradation and regulates apoptosis. Cell Death Differ. 2008;15:1941-51.

21. Melino G, Knight RA, Cesareni G. Degradation of p63 by Itch. Cell Cycle. 2006;5:1735-9.
22. Rossi M, Aqeilan RI, Neale M, Candi E, Salomoni P, Knight RA, et al. The E3 ubiquitin ligase Itch controls the protein stability of p63. Proc Natl Acad Sci USA. 2006;103:12753-8.

23. Li C, Chang DL, Yang Z, Qi J, Liu R, He H, et al. Pin1 modulates p63alpha protein stability in regulation of cell survival, proliferation and tumor formation. Cell Death Dis. 2013;4:e943.

24. Rossi M, De Simone M, Pollice A, Santoro R, La Mantia G, Guerrini L, et al. Itch/AIP4 associates with and promotes p63 protein degradation. Cell Cycle. 2006;5:1816-22.

25. Perez CA, Ott J, Mays DJ, Pietenpol JA. p63 consensus DNAbinding site: identification, analysis and application into a p63MH algorithm. Oncogene. 2007;26:7363-70.

26. Keyes WM, Wu Y, Vogel H, Guo X, Lowe SW, Mills AA. p63 deficiency activates a program of cellular senescence and leads to accelerated aging. Genes Dev. 2005;19:1986-99.

27. Wu N, Rollin J, Masse I, Lamartine J, Gidrol X. p63 regulates human keratinocyte proliferation via MYC-regulated gene network and differentiation commitment through cell adhesionrelated gene network. J Biol Chem. 2012;287:5627-38.

28. Satou A, Taira T, Iguchi-Ariga SM, Ariga H. A novel transrepression pathway of c-Myc. Recruitment of a transcriptional corepressor complex to c-Myc by MM-1, a c-Myc-binding protein. J Biol Chem. 2001;276:46562-7.

29. Kimura Y, Nagao A, Fujioka Y, Satou A, Taira T, Iguchi-Ariga SM, et al. MM-1 facilitates degradation of c-Myc by recruiting proteasome and a novel ubiquitin E3 ligase. Int $\mathrm{J}$ Oncol. 2007;31:829-36.

30. Narita R, Kitaura H, Torii A, Tashiro E, Miyazawa M, Ariga H, et al. Rabring7 degrades c-Myc through complex formation with MM-1. PLoS ONE. 2012;7:e41891.

31. Dang CV. c-Myc target genes involved in cell growth, apoptosis, and metabolism. Mol Cell Biol. 1999;19:1-11.

32. Nesbit CE, Tersak JM, Prochownik EV. MYC oncogenes and human neoplastic disease. Oncogene. 1999;18:3004-16.

33. Fujioka Y, Taira T, Maeda Y, Tanaka S, Nishihara H, IguchiAriga SM, et al. MM-1, a c-Myc-binding protein, is a candidate for a tumor suppressor in leukemia/lymphoma and tongue cancer. J Biol Chem. 2001;276:45137-44.

34. Cruz C, Ventura F, Bartrons R, Rosa JL. HERC3 binding to and regulation by ubiquitin. FEBS Lett. 2001;488:74-80.

35. Garcia-Gonzalo FR, Rosa JL. The HERC proteins: functional and evolutionary insights. Cell Mol Life Sci. 2005;62:1826-38.

36. Hochrainer K, Mayer H, Baranyi U, Binder B, Lipp J, Kroismayr $\mathrm{R}$. The human HERC family of ubiquitin ligases: novel members, genomic organization, expression profiling, and evolutionary aspects. Genomics. 2005;85:153-64.

37. Yoo NJ, Park SW, Lee SH. Frameshift mutations of ubiquitination-related genes HERC2, HERC3, TRIP12, UBE2Q1 and UBE4B in gastric and colorectal carcinomas with microsatellite instability. Pathology. 2011;43:753-5.

38. Guarente L, Kenyon C. Genetic pathways that regulate ageing in model organisms. Nature. 2000;408:255-62.

39. Kuilman T, Michaloglou C, Mooi WJ, Peeper DS. The essence of senescence. Genes Dev. 2010;24:2463-79.

40. Keyes WM, Pecoraro M, Aranda V, Vernersson-Lindahl E, Li W, Vogel H, et al. DeltaNp63alpha is an oncogene that targets chromatin remodeler Lsh to drive skin stem cell proliferation and tumorigenesis. Cell Stem Cell. 2011;8:164-76.

41. Rivetti di Val Cervo P, Lena AM, Nicoloso M, Rossi S, Mancini $M$, Zhou $\mathrm{H}$, et al. p63-microRNA feedback in keratinocyte senescence. Proc Natl Acad Sci USA. 2012;109:1133-8. 